\title{
The forewing of the Aphis fabae (Scopoli 1763) (Hemiptera, Sternorrhyncha): a morphological and histological study
}

\author{
Barbara Franielczyk-Pietyra $^{1} \cdot$ Piotr Wegierek $^{1}$
}

Received: 24 March 2017/Revised: 4 May 2017/Accepted: 9 May 2017/Published online: 19 May 2017

(C) The Author(s) 2017. This article is an open access publication

\begin{abstract}
Dorsal and ventral sides of the forewing of Aphis fabae (Scopoli 1763) (Sternorrhyncha, Hemiptera) were examined by scanning electron microscopy. Reinforcement elements on their surface as well as scale-like elements were described. Using histological methods, cross-sections of the material were done. They showed a two-layered membrane with a circular foramen inside. The course of veins and places of their bifurcation were followed. Common stem of radius (R), media (M), and cubitus anterior $(\mathrm{CuA})$ veins were composed of separate tracheae, which ran separately at the beginning, then continued in a single tunnel, and finally disappeared. Nerves were not observed. Neither were tracheae visible on the further course of those veins. The presence of a devoid-of-trachea costal vein was confirmed. Under scanning electron microscope, convex reinforcements on dorsal side of the wing turned out to be more sclerotized parts of chitin, not giving a zigzag-like profile of the wing on sections. In this paper, we show for the first time a cross-section of a very delicate wing of an aphid representative.
\end{abstract}

Keywords Aphids · Cross-section · Forewing - Tracheae · Wing veins

Barbara Franielczyk-Pietyra

b.franielczyk@o2.pl

1 Department of Zoology, Faculty of Biology and Environmental Protection, University of Silesia, Bankowa 9, 40-007 Katowice, Poland

\section{Introduction}

Insect body must be resistant to many environmental factors. It is especially true in case of wings, particularly in long-distance flying insects (Dirks and Taylor 2012). An insect wing is a two-layer membrane supported by longitudinal veins, sometimes also cross-veins and reinforced by extracellular cuticle. Wing veins are described as hollows circular on section, providing hemolymph, nerves and tracheae (Kukalová-Peck 1978; Dudley 2000; Shimmi et al. 2014). Tracheae appear in the wing before veins so it seems that they determine the course of the veins. However, not every vein comprises trachea (Patch 1909). Likewise, nerves or hemolymph are not always present in veins. Also, vein sections can be far from circular-from oval to campanulate (Snodgrass 1935; Dudley 2000), but most popular are dumbbell-shaped (Rajabi et al. 2016b).

Around veins thickened cuticle creates reinforcements, usually depicted as convex (above wing membrane as cuticular ridges in dorsal view) or concave (as cuticular grooves in ventral view), which cause wings corrugation (Kukalová-Peck 1978; Appel et al. 2015). Until now, it has been believed that only veins strengthen the wings, but actually it is achieved thanks to the interaction of veins, wing membrane, and corrugations (Rajabi et al. 2016a).

The second essential element relevant to flight is the wing base articulation (Chapman 2013). It is a very complex part of insect body, composed of axillary sclerites and additional elements working together during the flight and wing folding. Because axillary sclerites are tiny, it is easier to study larger insects, such as Odonata (Ninomiya and Yoshizawa 2009) or Dictyoptera (Yoshizawa 2011) in regard to Hemimetabola. Within the hemimetabolous suborder Sternorrhyncha (Hemiptera), wing base articulation was studied by Weber $(1928,1935)$ in aphids and whiteflies, Koteja (1996) 
in coccids, Yoshizawa and Saigusa (2001) and Ouvrard et al. (2008) in psyllids. More recently, forewing base articulation in representatives of all four infraorders of Sternorrhyncha was studied by Franielczyk and Wegierek (2016).

The presence of tracheae in Sternorrhyncha wings was studied in detail by Patch (1909), where she tried to homologize nymphal trachea with veins of imago. Tracheal system and veins pattern were also established for Orthezia urticae (Sternorrhyncha) by Koteja (1986). Because hemipteran wings are very small and fragile, latter one is the only article showing drawing of their cross-sections. The course of aphid wing veins was discussed by Klimaszewski and Wojciechowski (1992) and Wojciechowski (1992) for both fossil and recent groups and by Shcherbakov (2007), Szwedo et al. (2015) for fossil species.

A few other studies were recently carried out on wings of Orthoptera (Wootton et al. 2000), Lepidoptera (O`Hara and Palazotto 2012), Coleoptera (Sun et al. 2014), and Odonata (Appel et al. 2015; Rajabi et al. 2016a, b), whose wings are bigger and more rigid than those of Sternorrhyncha.

Here, we present the first reconstruction of the course of wing veins in aphids, which is also the first one within the Sternorrhyncha group.

In this study, we investigated dorsal and ventral surfaces of Aphis fabae (Scopoli 1763) forewing. Cross-sections of this forewing were made to find out what the inner structure looks like and to follow the course of the veins.

\section{Materials and methods}

\section{Scanning electron microscopy}

Forewings of three individuals of Aphis fabae species were examined using scanning electron microscopy. Samples were fixed and stored in 70\% ethanol and then prepared using ethanol dehydration and hexamethyldisilazane (HMDS) drying. After $70 \%$ ethanol fixation, the material was dehydrated in a graded ethanol/water series of $75,80,90,96$, and $100 \%$ for 10 min in each concentration, and then there were three $100 \%$ ethanol changes. After dehydration, the samples were treated with HMDS $3 \times 10$ min and retained in HMDS after third change until the solution evaporated (Kanturski et al. 2015).

Samples were mounted on holders, sputter-coated with gold and examined using a scanning electron microscope (Hitachi UHR FE-SEM SU 8010, Tokyo, Japan) in the Scanning Electron Microscopy Laboratory at the Faculty of Biology and Environmental Protection, University of Silesia.

\section{Histology}

Specimens were collected in $70 \%$ ethanol and then transferred to $2.5 \%$ glutaraldehyde in a $0.05 \mathrm{M}$ cacodylate buffer $(\mathrm{pH}$

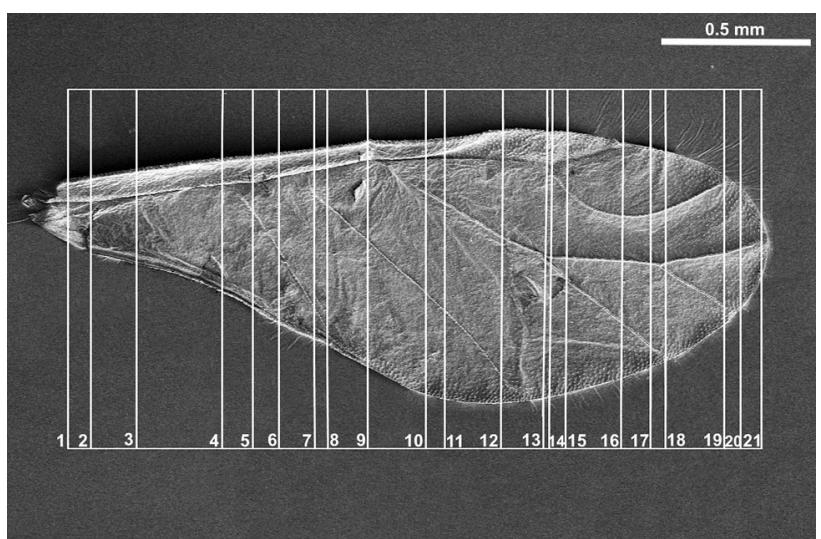

Fig. 1 Scanning electron microscopy showing the forewing of Aphis fabae (Scopoli 1763), places of sectional cuts

7.4). After washing in $0.1 \mathrm{M}$ phosphate buffer ( $\mathrm{pH}$ 7.4), the material was postfixed for $2 \mathrm{~h}$ using $1 \% \mathrm{OsO}_{4}$ in phosphate buffer, dehydrated in a graded series of ethanol replaced by acetone and then embedded in an Epoxy Embedding Medium Kit (Sigma, St. Louis, MO). Semithin sections were cut from the root to the tip of the forewing on a Leica Ultracut UCT ultramicrotome (each having a thickness of $700 \mathrm{~nm}$ ) with diamond knife and stained with methylene blue.

Sectional cuts (Fig. 1) were analyzed using Nikon Ni-U light microscope and photographed with a Nikon DS-Fi2 camera. The whole wing was cut into about 600 semithin sections but 21 slices were selected. They are aligned in Figs. 6, 7, 8, and 9 the same way as the white lines on SEM images (costal margin at the top, anal margin at the bottom, upper surface to the left). Some of the slices were positioned at an angle to use the available space efficiently.

Facing the problem of non-consistent nomenclature of the veins, we adopted that of Shcherbakov (2007), Szwedo and Nel (2011), and Nel et al. (2012). The following abbreviations are used: C—costa; R1 (=RA)—radius (=radius anterior); Rs (=RP)—radius sector (=radius posterior); $\mathrm{M}-$ media; $\mathrm{M}_{1}-$ first branch of media; $\mathrm{M}_{2}-$ second branch of media; $\mathrm{M}_{3+4}$-fused third and fourth branch of media; $\mathrm{CuA}_{1}$ - first branch of cubitus anterior; $\mathrm{CuA}_{2}$ second branch of cubitus anterior.

\section{Results}

\section{Surface of the forewing}

Dorsal surface of Aphis fabae forewing is characterized by strongly convex reinforcement elements (Figs. 3a, 4a, 5; white arrows), each one covered by ring-like elements (additional support in the form of rings arranged one after another). Almost entire edge of the wing is covered by scale-like elements (Figs. 3, 4, 5a, b; white asterisk). 


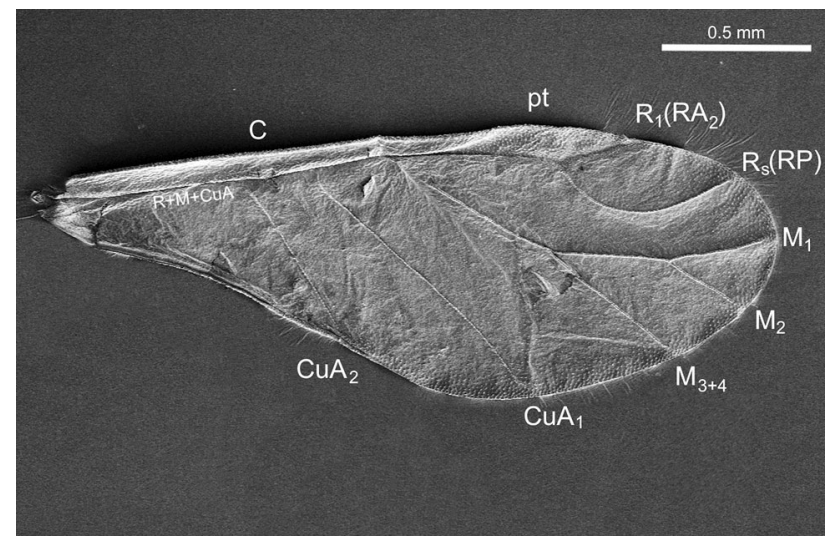

Fig. 2 Scanning electron microscopy showing the forewing of Aphis fabae (Scopoli 1763), veins organization, dorsal view

However, the dorsal side is not as much covered by wax as the ventral one. What is more, on the surface of the latter all reinforcement elements are concave (Figs. 3b, 4b).
Pterostigma on both sides, the dorsal and ventral sides, is covered by scale-like elements with denser arrangement dorsally (Fig. 3a, b; white asterisk).

All reinforcement elements are convex on the dorsal side and concave ventrally (Figs. 3, 4). Along the cephalic margin of the wing the costal vein (C) extends to the region of pterostigma (Fig. 2). Parallel to $\mathrm{C}$, common stem is visible, composed of radial (R), media (M), and cubitus anterior $(\mathrm{CuA})$ veins $(\mathrm{R}+\mathrm{M}+\mathrm{CuA})$. Radial vein is divided into $\mathrm{R} 1$ and Rs, right behind pterostigma. Medial vein consists of $\mathrm{M}_{1}, \mathrm{M}_{2}$, and $\mathrm{M}_{3+4}$. Cubitus anterior is divided into two branches, $\mathrm{CuA}_{1}$ and $\mathrm{CuA}_{2}$. Anal veins and claval fold are absent. There is no direct connection between the so-called common stem and each vein (Fig. 5c). Also, none of the mentioned veins reach the apical part of the wing directly (Figs. 3, 4, 5a, b) and there are no cross-veins.
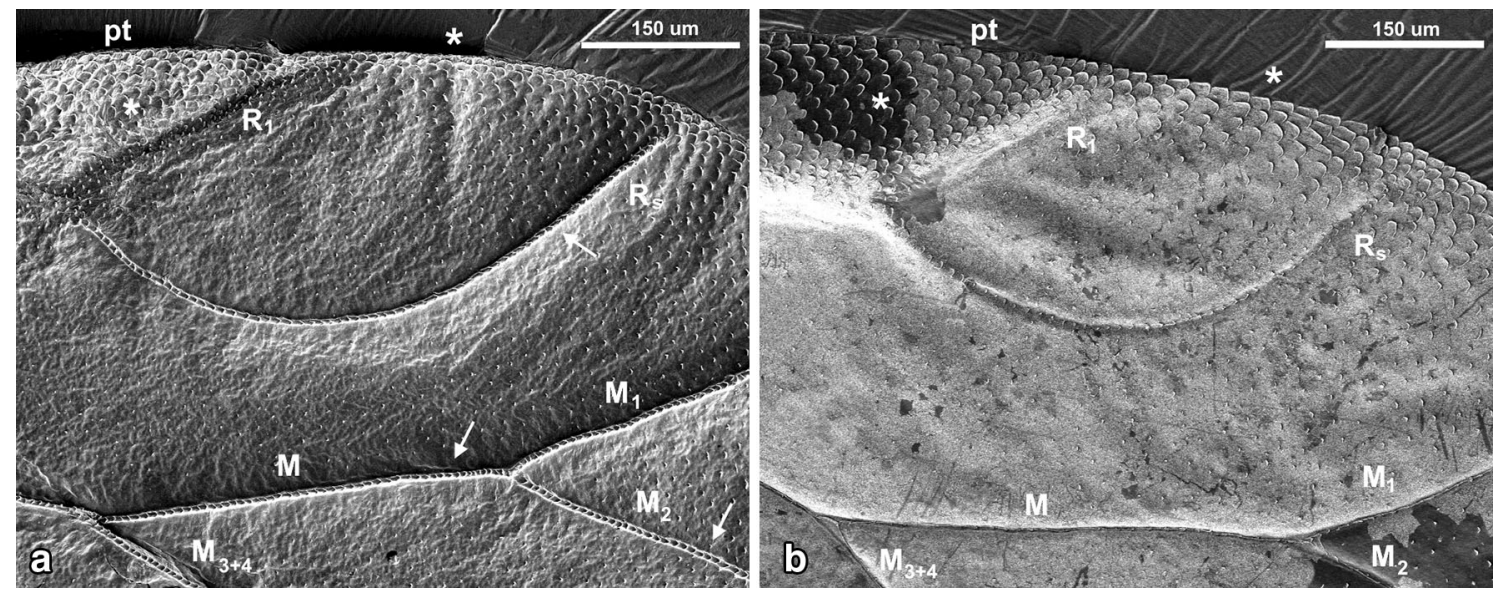

Fig. 3 Scanning electron microscopy showing part of the wing of Aphis fabae (Scopoli 1763), with pterostigma (pt) a dorsal view, b ventral view; white arrows indicate reinforcement elements; white asterisks indicate scale-like elements
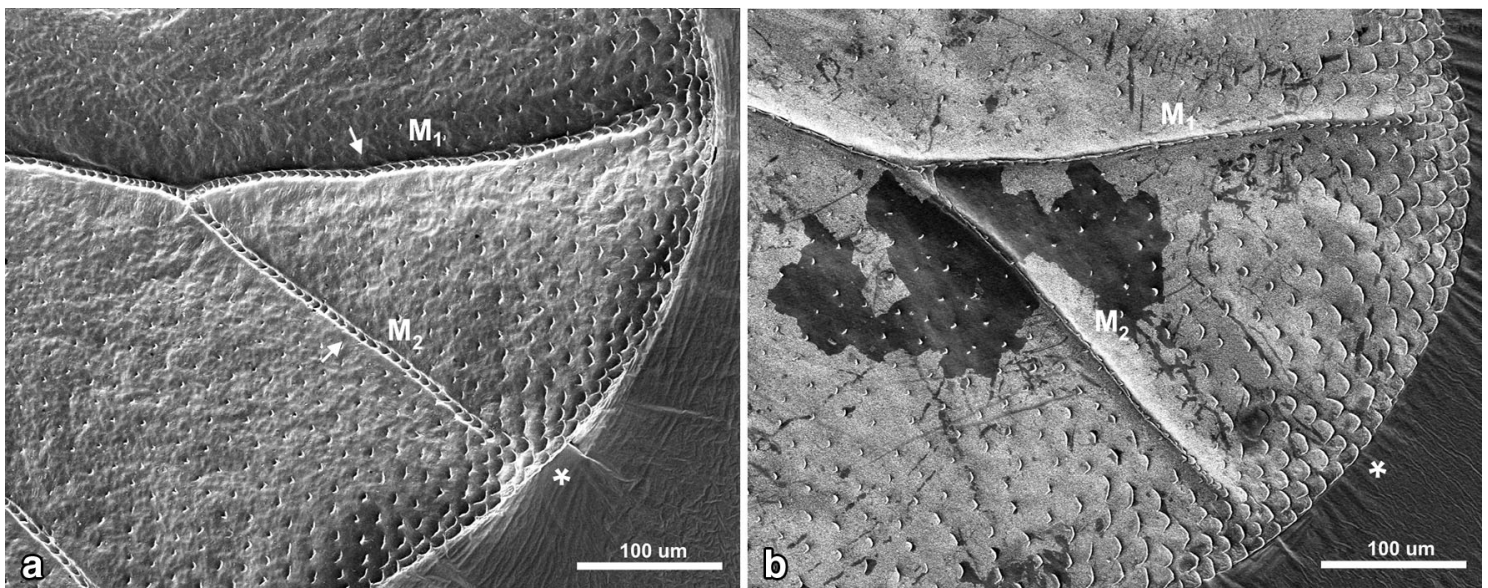

Fig. 4 Scanning electron microscopy showing apical part of the wing of Aphis fabae (Scopoli 1763) a dorsal view, b ventral view, white arrows indicate reinforcement elements; white asterisks indicate scale-like elements 

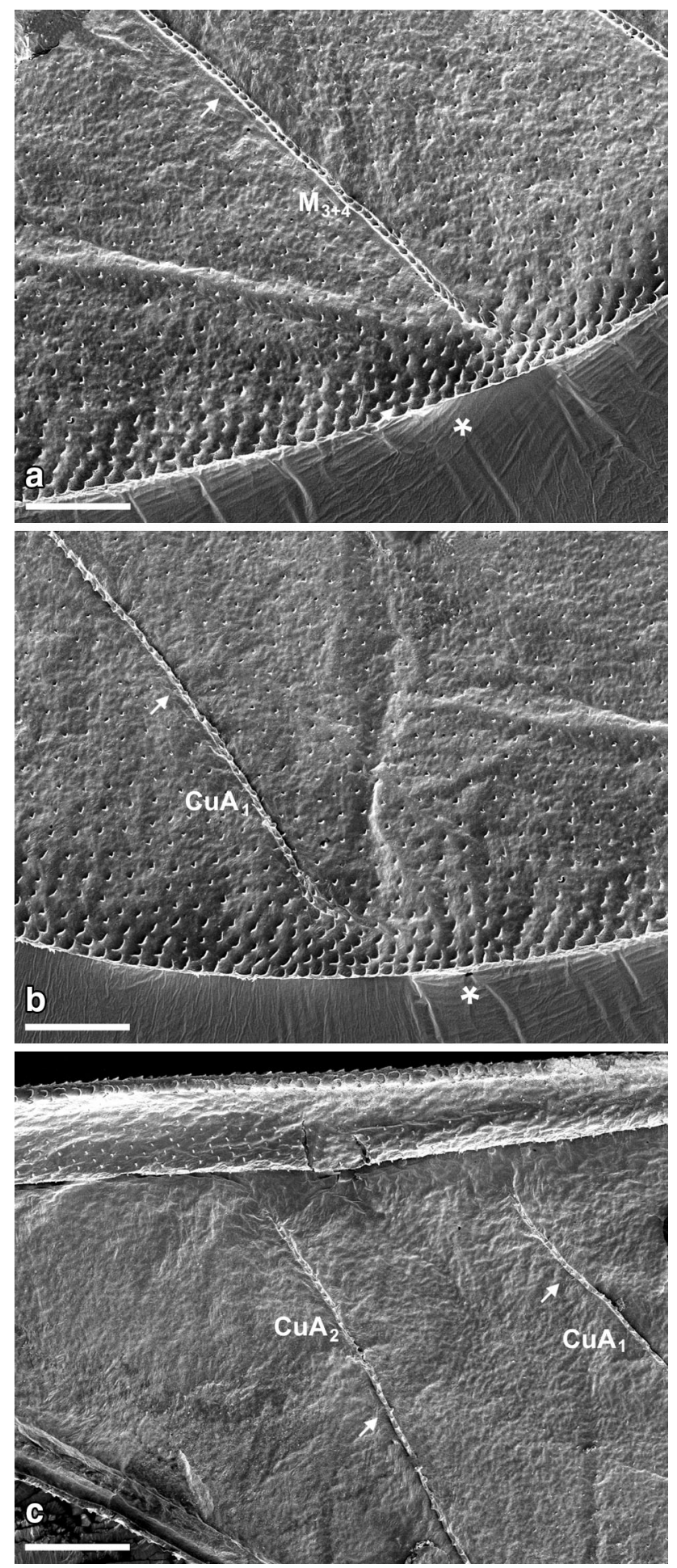

Fig. 5 Scanning electron microscopy showing the wing of Aphis fabae (Scopoli 1763) a apical part of media vein $\left(\mathrm{M}_{3+4}\right)$, dorsal view, b apical part of first branch of cubitus vein $\left(\mathrm{CuA}_{1}\right)$, dorsal view, $\mathbf{c}$ part of common stem and both branches of cubitus vein $\left(\mathrm{CuA}_{1}, \mathrm{CuA}_{2}\right)$, dorsal view; white arrows indicate reinforcement elements; white asterisks indicate scale-like elements; scale bar $100 \mu \mathrm{m}$

\section{Cross-sections of the forewing}

All veins are recognized on sections and all are rounded, but only costal vein is clearly round in shape. Other veins are almost round.

On sections, veins are arranged in one straight line, there is no zigzag-like profile. Only more sclerotized cuticle around veins is marked as dark points on cross-sections (as around $\mathrm{CuA}_{2}$ in Fig. 7a).

The channel for common stem is visible as the main U-shaped indentation of the wing on nine sections (Figs. 6a-d, 7a-e, Fig. 6a white arrow), but its content is changing. All three veins $(\mathrm{R}+\mathrm{M}+\mathrm{CuA})$ are present in Figs. $6 \mathrm{a}-\mathrm{d}, 7 \mathrm{a}, \mathrm{b}$. In Fig. $7 \mathrm{c}-\mathrm{e}$, only $\mathrm{R}+\mathrm{M}$ are building common stem, and from Figs. $7 \mathrm{f}$ till $8 \mathrm{~d}$, the stem includes only vein $\mathrm{R}$. The latter is divided into R1 and Rs in Fig. 8e, $\mathrm{f}$, but from Fig. 9a only vein Rs is present.

The first three pictures, Fig. 6a-c, show the most basal part of the wing. Around the wing membrane (Fig. 6a), there is a clearly visible cuticle (c) and epidermal cells (e) inside the wing. Costal vein and common stem, consisting of $\mathrm{R}+\mathrm{M}+\mathrm{CuA}$, are visible.

Media is present on cross-sections from Fig. 7f, as a rounded vein, with small black dots on upper and lower walls. Starting from Fig. 8c, media begins to divide into two separate veins. On upper wall of this vein, there are two black dots. New branch of media, $\mathrm{M}_{3+4}$, is presented in Figs. 8d-f and 9a. Next, Figs. 8f and 9b, c, show division of $M$ into $M_{1}$ and $M_{2}$, until the latter are no longer visible. The last section (Fig. 9e) shows only wing membrane, without any vein.

The second branch of cubital vein $\left(\mathrm{CuA}_{2}\right)$ is present in Fig. $7 \mathrm{a}-\mathrm{c}$, where the first branch $\left(\mathrm{CuA}_{1}\right)$ is also visible. The latter is marked in Figs. 7c-f, 8a, b.

Pterostigma is present in Fig. 8a-f, as an extension of the wing membrane; it is not entirely empty but seems to contain cells.

Folded anal margin of the wing is visible in Fig. $7 \mathrm{a}-\mathrm{d}$ (white dotted circle).

A small indentation between $R+M$ visible in Figs. 7e, $\mathrm{f}, 8$, and $9 \mathrm{a}-\mathrm{c}$ is the artifact created during wing embedding.

\section{Discussion}

The nomenclature of wing veins in insects should differentiate between true veins and (vein-like) false veins. The first group should refer to veins composed of nerves, tracheae, and the cavity for hemolymph. The other should 


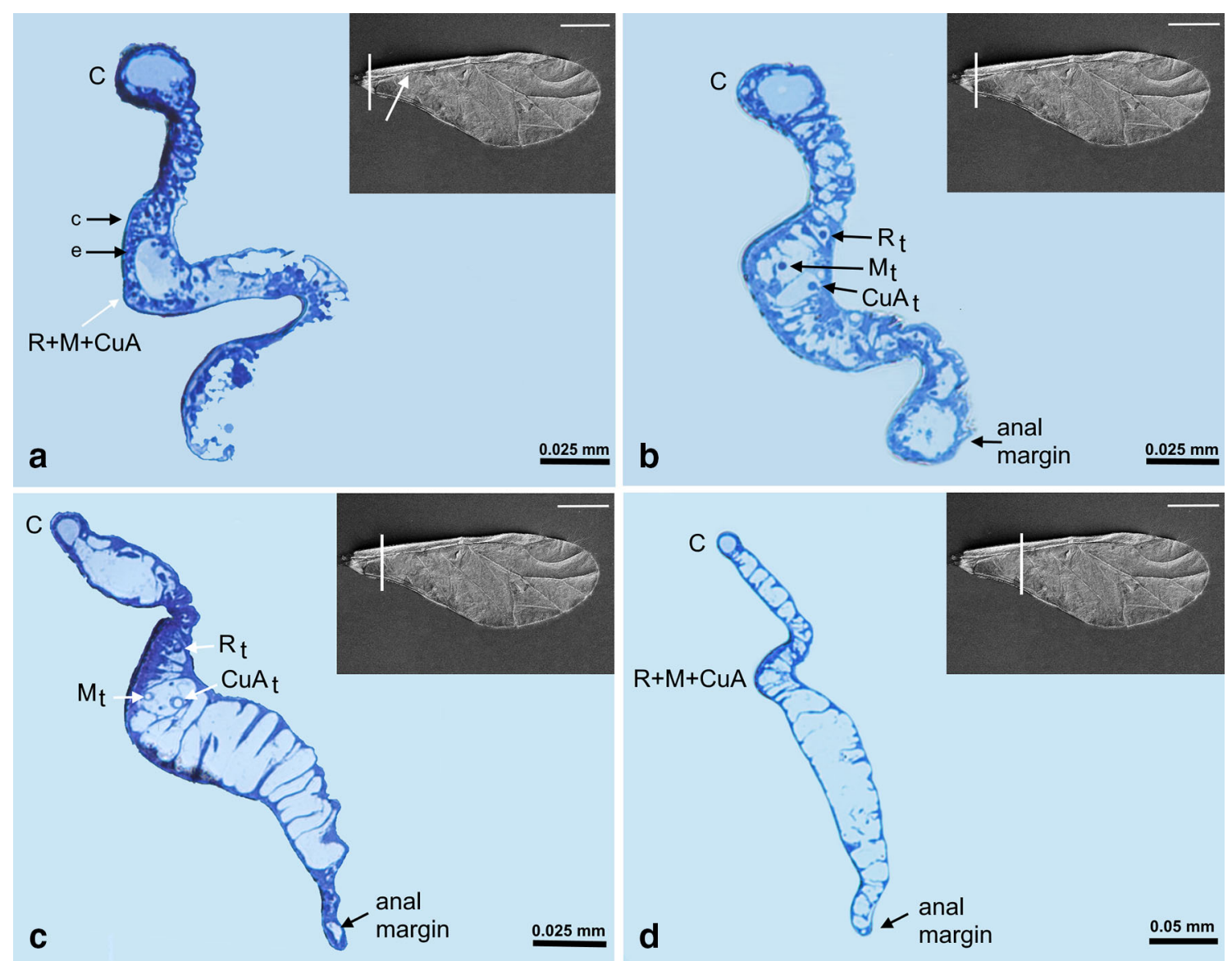

Fig. 6 Cross-sections of the forewing of Aphis fabae (Scopoli 1763) under magnification a-c $\times 40, \mathbf{d} \times 20$; LM light microscope, $c$ cuticle, $e$ epidermal cells. SEM scale bar $0.5 \mathrm{~mm}$

contain internally empty veins, which serve only as reinforcement elements (Dudley 2000). The elements called "wing veins" which are visible on Aphis fabae dorsal wing side, are in fact more sclerotized with chitin acting as reinforcement of the veins and the whole wing.

According to Wojciechowski (1992), the lack of costal vein is considered as synapomorphy among aphids and coccids. Patch (1909) claimed that this vein is present in aphids but it has no trachea; no trachea could have been identified in our study either. Moreover, Shcherbakov (2007) stated that the lack of C trachea is regarded as synapomorphy of Aphidomorpha + Coccomorpha. In our ongoing studies, we want to check if costal vein and its trachea are present in coccid representatives.

Detailed studies done by Patch (1909) also showed that there is no such thing as subcostal trachea $\left(\mathrm{Sc}_{\mathrm{t}}\right)$, but vein $\mathrm{Sc}$ is present, so it is not surprising that we cannot mark trachea of subcostal vein. It seems more interesting that subcostal vein is not shown on any part of the section. The lack of vein $\mathrm{Sc}$ and its trachea mentioned by Wojciechowski (1992) as apomorphy in aphids is confirmed in our studies.
At the beginning of sections, common stem is a rounded hole in the wing (Fig. 6a). Further, each of the three tracheae is separated by thin epidermal walls (Fig. 6b), but a little further $R_{t}$ is separated and $\mathrm{Mt}+\mathrm{CuA}_{\mathrm{t}}$ are enclosed in one "cell". It looks as if tracheae of $\mathrm{M}$ and $\mathrm{CuA}$ run together in common stem, independent of $R_{t}$ (Fig. 6c). Unfortunately, it is visible only on the initial sectionsnext ones show no trace of trachea. The fusion of veins $\mathrm{R}+\mathrm{M}+\mathrm{CuA}$ in forewings of Sternorrhyncha is evident especially in aphids and psyllids ( $\mathrm{Nel}$ et al. 2012).

Recently, Szwedo et al. (2015) described the oldest Aphidomorpha species, which showed an uncommon condition among aphids- branch $\mathrm{CuA}_{2}$ was thicker than $\mathrm{CuA}_{1}$. In our study, two branches of $\mathrm{CuA}\left(\mathrm{CuA}_{1}\right.$ and $\left.\mathrm{CuA}_{2}\right)$ are widely separated, almost parallel and convex, just as pointed out by Shcherbakov (2007). It is regarded as an apomorphic condition in aphids (Shaposhnikov 1980, 1985, 1987). Based on those conclusions, we can assume that the species described by Szwedo et al. (2015) belong to another, independent developmental line.

In addition, nodal line (transverse flexion line) is not visible in figures from SEM. Moreover, in our SEM study 


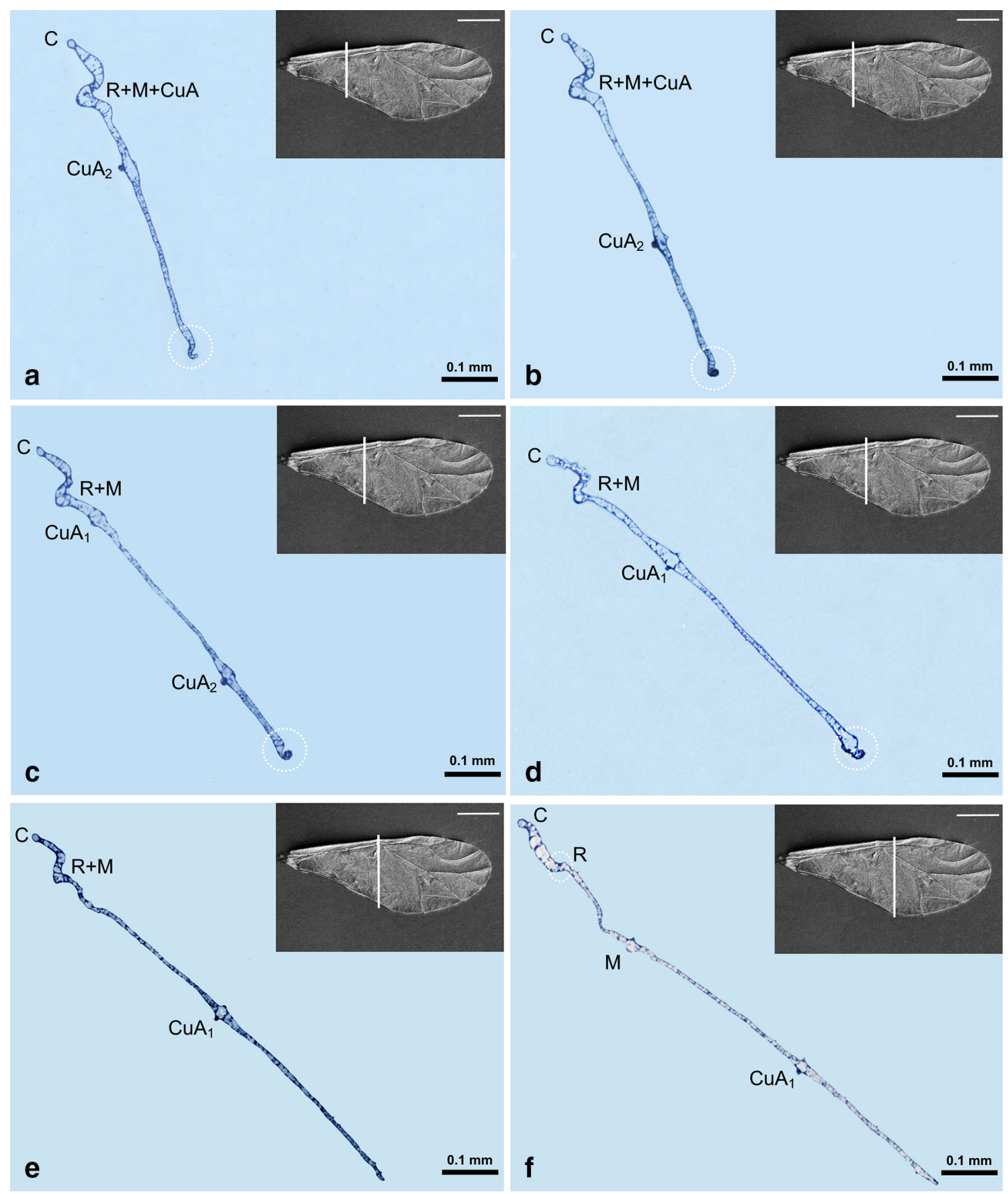

Fig. 7 Cross-sections of the forewing of Aphis fabae (Scopoli 1763) under magnification $\mathbf{a}-\mathbf{f} \times 10$; LM. SEM scale bar $0.5 \mathrm{~mm}$

medial vein is convex on its entire course, which is not consistent with Shcherbakov and Wegierek (1991), who stated that $\mathrm{M}$ is partly convex-concave to allow upstroke.

$\mathrm{R} 1$ is not clearly visible in sections due to the fact that it is a very inconspicuous vein. Besides, it is concave compared to other wing veins on the dorsal side.

Pterostigma is described as a pigmented spot near the end of the wing tip; the element is responsible for increasing speed. In Hemiptera it is present on forewings only. Very little is known about this part of the wing in that insect, especially its inner structure. Generally, it is regarded as blood sinus (Arnold 1963). Our studies showed that, on sections it is a broadened wing membrane where the dorsal and ventral sides are connected by a pattern of chitinous reinforcements in the shape of transverse trabeculae. Being wider than the other parts of the wing, it can really play a role as an element for better wing-flapping performance without additional energy (Norberg 1972). 


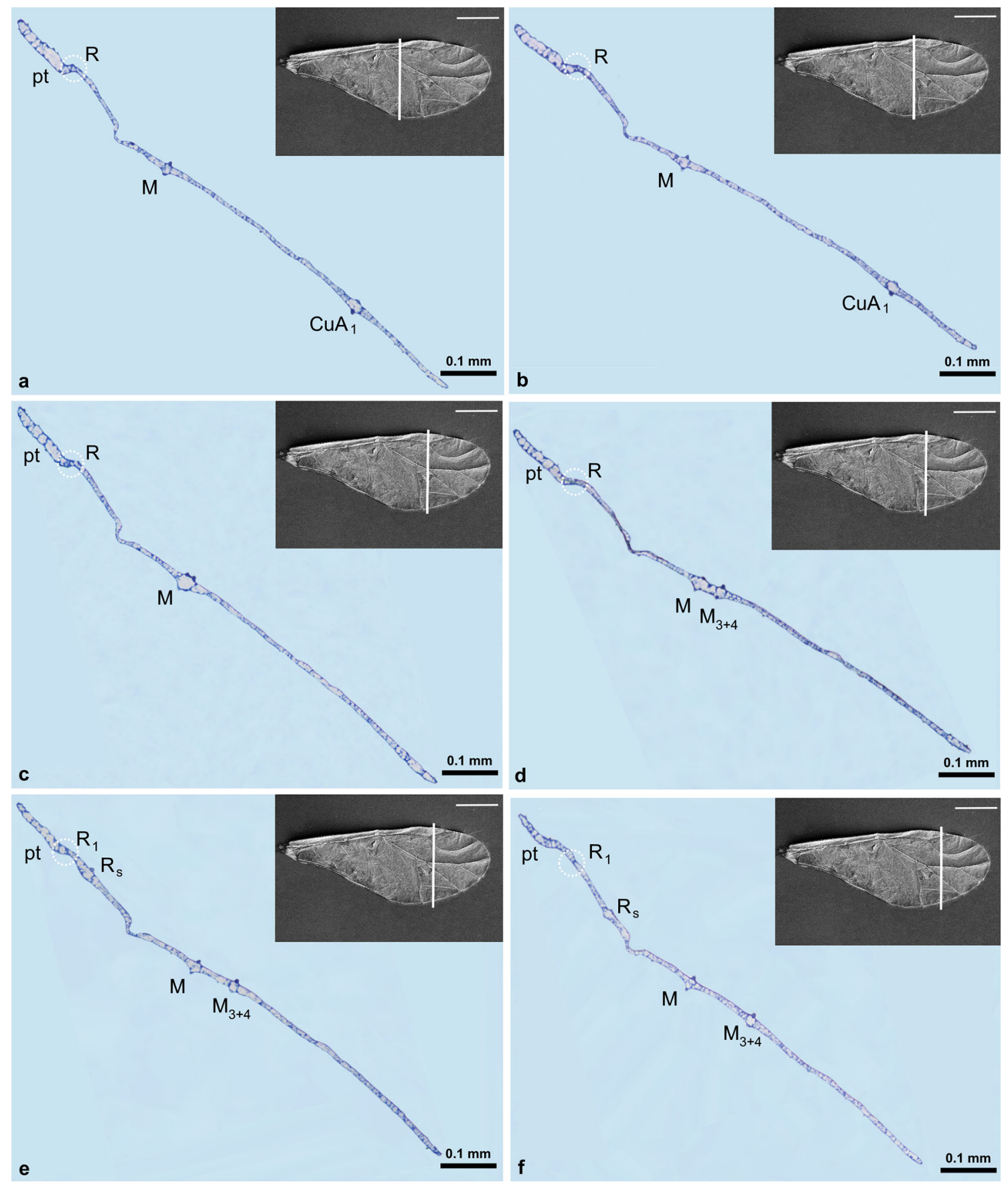

Fig. 8 Cross-sections of the forewing of Aphis fabae (Scopoli 1763) under magnification a-f $\times 10$; LM. SEM scale bar $0.5 \mathrm{~mm}$

During the course of their evolution, aphids tend to diminish their body size and reduce the claval fold and anal region of the wings (Shaposhnikov 1980, 1985, 1987; Shcherbakov and Wegierek 1991; Shcherbakov 2007). Accordingly, such structures do not exist in extant aphids. Shcherbakov (2007) also indicated the presence of submarginal claval veins $\mathrm{PCu}+1 \mathrm{~A}$, in aphids' and coccids' forewings. Cross-sections presented here do not confirm their existence. Probably those two veins moved so close to the marginal part of the anal margin of the wing (Fig. 7ad) that they have become a part of wing-coupling apparatus in aphids, linking both wing pairs during the flight. The coupling apparatus consists of the fold of the forewing and the hamuli of the hindwing; the latter may vary in number in different species (Ni et al. 2002). In addition, Szwedo et al. (2015) claimed that $\mathrm{PCu}$ and $\mathrm{A}_{1}$ were present in the oldest Aphidomorpha known so far (from the Middle Permian). Probably, these veins are not preserved in recent 


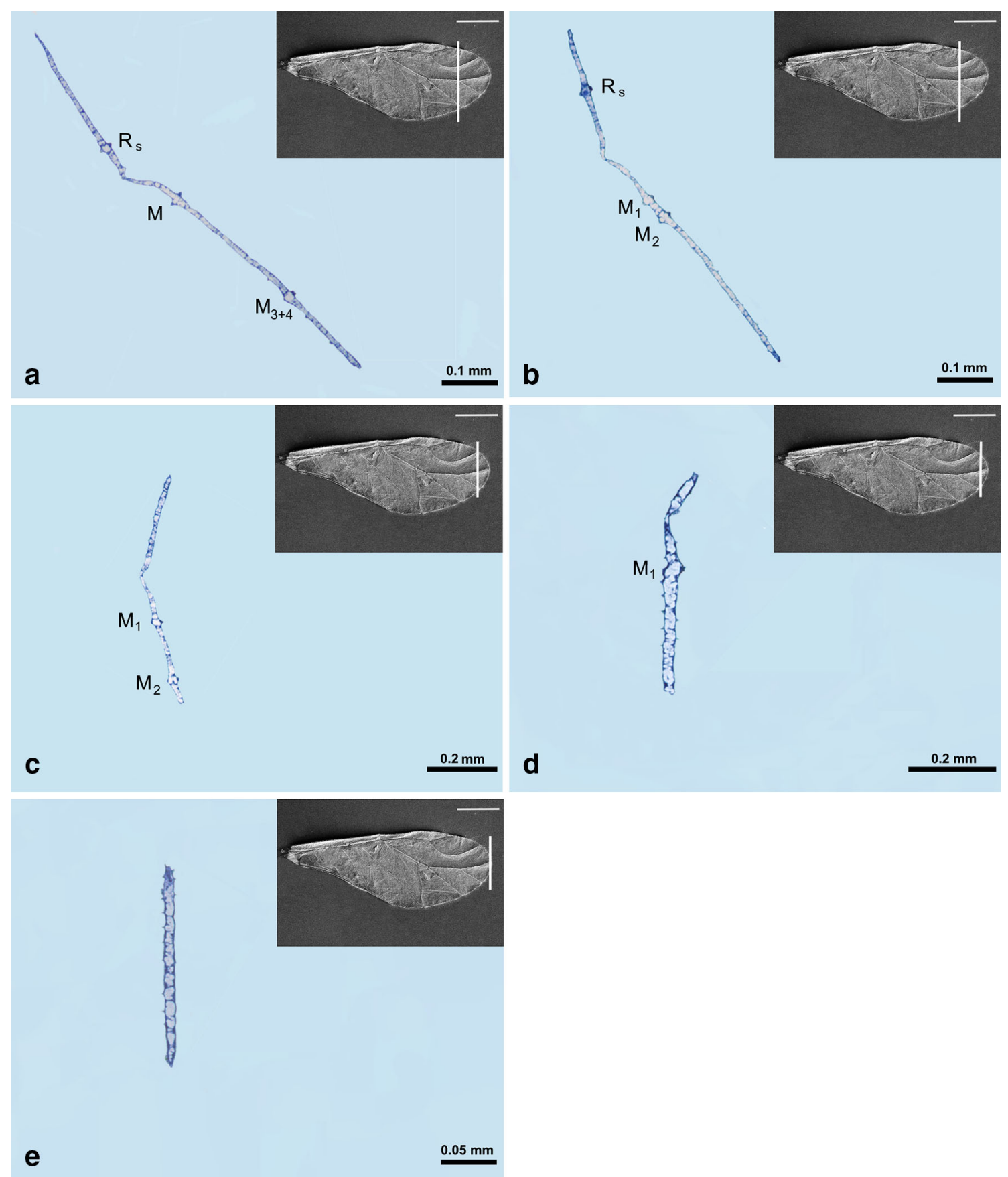

Fig. 9 Cross-sections of the forewing of Aphis fabae (Scopoli 1763) under magnification a and $\mathbf{b} \times 10$; $\mathbf{c}-\mathbf{e} \times 20$; LM. SEM scale bar $0.5 \mathrm{~mm}$

aphids. The same authors indicated the presence of subcostal posterior vein $(\mathrm{ScP})$ near the costal margin of the forewing of aphid's ancestor. We have not found any evidence to confirm that in the examined aphis.

The present examination identified the following features on A. fabae forewings: the presence of costal vein without its trachea; lack of subcostal vein; common stem of radius, media, and cubital anterior veins with tracheae in one tunnel at the beginning; widely separated, almost parallel and convex cubital anterior veins; pterostigma as a broadened part of the wing covered by scale-like elements; vein $\mathrm{R} 1$ concave on the dorsal side, while all other veins are convex; lack of anal fold and nodal line. It is also important that veins do not reach the wing apex and are not connected with the common stem.

Further investigations are required to supplement the results with the remaining representatives of Sternorrhyncha suborder (studies in process). After that, we will be 
able to verify current nomenclature of wing veins among these insects and decide which wing veins can be called true and which ones vein-like (false).

Acknowledgements The authors are sincerely grateful to Danuta Urbańska-Jasik, University of Silesia, for cross-sections of the wings. We also wish to thank Dmitry Shcherbakov and Łukasz Depa for their suggestions and comments that have improved the manuscript. We appreciate the critical comments and suggestions of the editor and anonymous reviewers that improved the first version of the manuscript. The authors gratefully acknowledge the Faculty of Biology and Environmental Protection (funded by the Ministry of Science and Higher Education of Poland) grant for young scientists, 2016.

\section{Compliance with ethical standards}

Conflict of interest The authors declare that they have no conflict of interest.

Animal rights We neither used endangered species nor were the investigated animals collected in protected areas.

Open Access This article is distributed under the terms of the Creative Commons Attribution 4.0 International License (http://crea tivecommons.org/licenses/by/4.0/), which permits unrestricted use, distribution, and reproduction in any medium, provided you give appropriate credit to the original author(s) and the source, provide a link to the Creative Commons license, and indicate if changes were made.

\section{References}

Appel E, Heppe L, Lin C-P, Gorb SN (2015) Ultrastructure of dragonfly wing veins: composite structure of fibrous material supplemented by resilin. J Anat 227:561-582

Arnold JW (1963) A note on the pterostigma in insects. Can Entomol 95(01):13-16

Chapman RF (2013) The insects: structure and function, 5th edn. Cambridge University Press, Cambridge

Dirks HJ, Taylor D (2012) Veins improve fracture toughness of insect wings. PLoS One 7(8):e43411. doi:10.1371/journal.pone. 0043411

Dudley R (2000) Morphology of the flight apparatus. In: Princeton University Press (ed) The biomechanics of insect flight: form, function, evolution. Princeton, New Jersey, pp 36-74

Franielczyk B, Wegierek P (2016) Comparative morphology of the forewing base articulation in Sternorrhyncha compared with a representative of Fulgoromorpha (Insecta, Hemiptera). Zoomorphology 135:89-101. doi:10.1007/s00435-015-0293-4

Kanturski M, Karcz J, Wieczorek K (2015) Morphology of the European species of the aphid genus Eulachnus (Hemiptera: Aphididae: Lachnidae) - a SEM comparative and integrative study. Micron 76:23-36

Klimaszewski SM, Wojciechowski W (1992) Relationship of recent and fossil groups of Sternorrhyncha as indicated by the structure of their forewings. Prace Nauk Uniw Slask Katow 1318:1-50

Koteja J (1986) Morphology and taxonomy of male Ortheziidae (Homoptera, Coccinea). Pol Pismo Entomol 56:323-374

Koteja J (1996) Scale insects (Hemiptera: Coccinea) a day after. In: Schaefer CW (ed) Studies on Hemipteran phylogeny. Thomas Say Publications in Entomology: Proceedings. Entomol Soc Am, Lanham, pp 65-88
Kukalová-Peck J (1978) Origin and evolution of insect wings and their relation to metamorphosis, as documented by the fossil record. J Morph 156:53-126

Nel A, Prokop J, Nel P, Grandcolas P, Huang D-Y, Roques P, Guilbert E, Dostál O, Szwedo J (2012) Traits and evolution of wing venation pattern in paraneopteran insects. J Morphol 273:480-506. doi:10.1002/jmor.11036

Ni X, Johnson GD, Quisenberry SS (2002) Comparison of hindwing hamuli from five species of cereal aphids (Hemiptera: Aphididae). Ann Entomol Soc Am 95(1):109-114

Ninomiya T, Yoshizawa K (2009) A revised interpretation of the wing base structure in Odonata. Syst Entomol 34(2):334-345. doi:10.1111/j.1365-3113.2008.00455.x

Norberg RA (1972) The pterostigma of insect wings an inertial regulator of wing pitch. J Comp Physiol 81:9-22

O'Hara RP, Palazotto AN (2012) The morphological characterization of the forewing of the Manduca sexta species for the application of biomimetic flapping wing micro air vehicles. Bioinspir Biomim 7(4):046011. doi:10.1088/1748-3182/7/4/046011

Ouvrard D, Burckhardt D, Soulier-Perkins A, Bourgoin T (2008) Comparative morphological assessment and phylogenetic significance of the wing base articulation in Psylloidea (Insecta, Hemiptera, Sternorrhyncha). Zoomorphology 127:37-47. doi:10. 1007/s00435-007-0049-x

Patch EM (1909) Homologies of the wing veins of the Aphididae, Psyllidae, Aleurodidae and Coccidae. Ann Entomol Soc Amer 2:101-135

Rajabi H, Rezasefat M, Darvizeh A, Dirks JH, Eshghi Sh, Shafiei A, Mirzababaie Mostofi T, Gorb SN (2016a) A comparative study of the effects of constructional elements on the mechanical behavior of dragonfly wings. Appl Phys A 122:19. doi:10.1007/ s00339-015-9557-6

Rajabi H, Shafiei A, Darvizeh A, Dirks J-H, Appel E, Gorb SN (2016b) Effect of microstructure on the mechanical and damping behavior of dragonfly wing veins. R Soc Open Sci 3:160006

Shaposhnikov GC (1980) Evolyutsiya morfologicheskikh struktur tleï (Homoptera, Aphidinea) I obraz zhizni ikh sovremennykh I mezozoïskikh predstaviteleï. Entomologischeskoe Obozrenie 59: 39-59. Published in English as: Shaposhnikov GC (1981) Evolution of morphological structures in aphids (Homoptera, Aphidinea) and the mode of life of recent and Mesozoic aphids. Entomol Rev 59:29-48

Shaposhnikov GC (1985) The main features of the evolution of aphids. Evolution and biosystematics of Aphids. In: Proceedings of the International Aphidological Symposium at Jabłonna. Ossolineum, Wroclaw, pp 19-99

Shaposhnikov GC (1987) Evolutionary estimation of taxa. In: Minks AK, Herrewijn P (eds) Aphids, their biology, natural enemies and control. World Crops Pests, vol 2A. Elsevier, Amsterdam, pp 401-408

Shcherbakov DE (2007) Extinct four-winged precoccids and the ancestry of scale insects and aphids (Hemiptera). Russ Entomol J 16(1):47-62

Shcherbakov DE, Wegierek P (1991) Creaphididae, s new and the oldest aphid family from the Triassic of Middle Asia. Psych 98:81-85

Shimmi O, Matsuda S, Hatakeyama M (2014) Insights into the molecular mechanisms underlying diversifies wing venation among insects. Proc R Soc B 281:20140264

Snodgrass RE (1935) Principle in insect morphology. McGraw-Hill Book Company Inc., New York

Sun J, Ling M, Wu W, Bhushan B, Tong J (2014) The hydraulic mechanism of the unfolding of hind wings in Dorcus titanus platymelus (Order: Coleoptera). Int J Mol Sci 15:6009-6018. doi:10.3390/ijms15046009 
Szwedo J, Nel A (2011) The oldest Aphid insect from the Middle Triassic of the Vosges, France. Acta Palaeontol Pol 56:757-766. doi:10.4202/app.2010.0034

Szwedo J, Lapeyrie J, Nel A (2015) Rooting down the aphid's treethe oldest record of the Aphidomorpha lineage from Palaeozoic (Insecta, Hemiptera). Syst Entomol 40(1):207-213

Weber H (1928) Skelett, Muskulatur und Darm der Schwarzen Blattlaus Aphis fabae SCOP. Zoologica 76:1-120

Weber H (1935) Der Bau der Imago der Aleurodinen. Ein Beitrag zur vergleichenden Morphologie des Insektenkorpers. Zoologica 89. E. Schweizerbart'sche Verlagsbuchhandlung, Stuttgart

Wojciechowski W (1992) Studies on the systematic system of aphids (Homoptera, Aphidinea). Prace Nauk Uniw Slask Katow 1269:1-76
Wootton RJ, Evans KE, Herbert R, Smith CW (2000) The hind wing of the desert locust (Schistocerca gregaria Forskal). I functional morphology and mode of operation. J Exp Biol 203:2921-2931

Yoshizawa K (2011) Monophyletic Polyneoptera recovered by wing base structure. Syst Entomol 36(3):377-394. doi:10.1111/j.13653113.2011.00572.x

Yoshizawa K, Saigusa T (2001) Phylogenetic analysis of paraneopteran orders (Insecta:Neoptera) based on forewing base structure, with comments on monophyly of Auchenorrhyncha (Hemiptera). Syst Entomol 26:1-13. doi:10.1046/j.1365-3113. 2001.00133.x 